DOI: $10.17805 /$ zpu.2015.2.26

\title{
С. Д. Кржижановский-шекспировед: к вопросу об освоении драматургии Шекспира в 1930-е годы (методы и подходы)
}

\author{
К. И. ПЛОтНИКОВ \\ (ИНСТИТУТ МИРОВОЙ ЛИТЕРАТУРЫ РАН)
}

В советском литературоведении конца 1920-х - начала 1930-х годов научные подходы к наследию У. Шекспира были отмечены господством вульгарно-социологического метода. Одной из ключевых фигур для литературоведения первых советских лет был В. М. Фриче. Воздействие официальной методологии испытывали все литературоведы.

Изменение отношения к творчеству Шекспира произошло после 1934 г. и было вызвано общим интересом к наследию классических авторов в советском театре.

В статье показана культурологическая и историческая позиция оригинального и малоизученного отечественного интерпретатора Шекспира 1930-х годов С. Д. Кржижановского. В частности, впервые приводится анализ ранее не опубликованной стенограммы доклада Кржижановского, посвященного хроникам Шекспира. Данный документ хранится в архиве фонда №52 «Всеросскомдрам» Отдела рукописей Института мировой литературы РАН.

Понятие об истории, которое С. Д. Кржижановский вкладывает в свою интерпретацию хроник Шекспира, восходит к проблемам методологии исторического познания в работах немецких философов конца XIX - начала XX в. В России оригинальными интерпретаторами и продолжателями этого методологического подхода явились такие историки, как А. С. Лаппо-Данилевский, И. М. Гревс, Н. П. Анциферов.

По мысли С. Д. Кржижановского, Шекспир производит отбор исторического материала в точности, как историк. На примере различных персонажей Шекспира - как исторических, так и вымышленных - С. Д. Кржижановский выстраивает внутренние, структурные особенности исторических хроник как поэтику текста посредством анализа и соотношения исторических фактов, их толкования в эпоху Шекспира и через призму фантазии автора, чье воображение, трансформируя исторические факты, соответствуя канону драматического произведения, создает особый, вымышленный мир для своего современника. Кржижановский утверждает, что, не представляя собственного будущего, зрителю приятно ощущать себя «будущим» для персонажей исторической хроники, следить за драмой «прошлого», переходящей в настоящее.

Ключевые слова: У. Шекспир, С. Д. Кржижановский, хроники Шекспира, советская драматургия, советское шекспироведение.

\section{ВВЕАЕНИЕ}

O тенденциях советского шекспироведения в 1930-е годы достаточно подробно написано у И. О. Шайтанова в статье «История с пропущенными главами: Бахтин и Пинский в контексте советского шекспироведения» (Шайтанов, 2011). Автор описывает характерные пути развития ряда шекспироведов 1930-х годов. Его внимание направлено на самые яркие персоналии официального советского шекспироведения, это В. М. Фриче (1870-1929), И. А. Аксенов (1884-1935), А. А. Смирнов (1883-1962), М. М. Морозов (1897-1952) и ар.

Однако в поле зрения И. О. Шайтанова не попадает Сигизмунд Аоминикович Кржижановский (1887-1950). Будучи оригинальным интерпретатором Шекспира, С. А. Кржижановский оставил свои интеллектуальные штудии, которые стали доступны широкому кругу читателей только в 1988 г. в журнале «Аитературная учеба». Кроме этой, на наш взгляд, ключевой фигуры советского шекспироведения есть ряд драматургов, переводчиков и режиссеров, которые внесли свою лепту в изучение творче- 
ства Шекспира. О некоторых из них также пойдет речь в данной статье - в ракурсе их отношения к теме «народности» шекспировского творчества.

\section{ТЕМА «НАРОАНОСТИ» \\ В СОВЕТСКОМ ШЕКСПИРОВЕАЕНИИ 1930-Х ГОАОВ}

Первой советской монографией о Шекспире стала книга А. А. Смирнова «Творчество Шекспира» (1934). Эта книга имела открыто полемический характер и была направлена против преобладавшей до 1934 г. вульгарно-социологической концепции В. М. Фриче, который разрабатывал проблемы идеологической роли литературы, классовой ее природы. А. А. Смирнов видит в Шекспире «гуманистического идеолога буржуазии своей эпохи» (Смирнов, 1934: 52). Отсюда следует, что «тема всего творчества Шекспира - утверждение новой морали и нового мировоззрения, опрокидывающего все феодальные мировоззренческие нормы и устои» (там же: 20), что Шекспир описывает ренессансный этап буржуазного сознания.

Оспаривая концепцию В. М. Фриче об упадочно-аристократическом пессимизме Шекспира, А. А. Смирнов в духе времени привязывает его творчество к идеологии одного из классов, борющихся за господство в эпоху перехода от феодального Средневековья к буржуазному укладу жизни.

Во времена В. М. Фриче все, что было написано до революции, «сбрасывали с корабля современности», но в 1930-е годы классиков реабилитировали, более того, их стали ставить в пример как образец для социалистического культурного строительства. В эпоху реконструкции (индустриализации, коллективизации и ударничества), за классикой стала признаваться прогрессивная историческая роль, а Шекспир стал эталоном и вершиной в мировой драматургии, на него должны были равняться советские драматурги.

Смену официальной позиции к классической литературе в общем и к Шекспиру в частности демонстрирует статья В. С. Кеменова «Шекспир в объятиях “социолога”» (1936). Главным тезисом, выдвинутым В.С. Кеменовым, стал тезис «народности шекспировского театра» (Кеменов, 1936а). При анализе современной Шекспиру исторической обстановки автор делает акцент на национальной специфике английского Ренессанса и своеобразии этапа возникновения шекспировского театра, связанного с конфликтом между уже свободными индивидуумами. Аля исследователя именно эти столкновения и образуют трагическую коллизию произведений Шекспира.

По мнению В. С. Кеменова, «народность шекспировского творчества заключается не столько в том, как Шекспир относился к английскому народу (который часто изображен у него прямо-таки карикатурно), а в том, как Шекспир относился к людям эксплуататорских классов своей эпохи, в разоблачении их страстей и подлости их поступков» (Кеменов, 1936b: 2). Он отмечает: «В глазах В. М. Фриче и П. С. Когана Шекспир реакционный феодал, а с другой стороны, Шекспира объявляют приверженцем прогрессивной буржуазии (А. Смирнов, С. Радлов, А. Пиотровский). <..> от вульгарной социологии страдает Шекспир, реализм которого каждый раз односторонне искажают...» (там же).

Однако еще до В. С. Кеменова тема «народничества» «спонтанно» возникает у писателя (не у шекспироведа) $\Lambda$. М. Аеонова (1899-1994). Об актуальности Шекспира эпохи реконструкции писали многие, но $\Lambda$. М. Аеонов видел в Шекспире художника, который может научить молодое советское искусство отражать «самые мощные человеческие страсти, самые глубокие эмоции и бурные человеческие темпераменты» (Иеонов, 1933: 3). Кроме того, именно $\Lambda$. М. Аеонов был одним из первых (наряду 
с В. С. Кеменовым), кто «нащупал» тему «народничества». Уже в 1933 г. в своей статье «Площадность Шекспира» ему удалось ощутить «нерв» эпохи и передать его в отношении творчества классика. Вот что он пишет: «В эпоху штурма, глубокого исторического натиска, который мы переживаем, всем родам искусства, а значит и драматургии, должны быть присущи элементы эпичности. <...> Железная поступь наших будней требует монументальности “шекспировской площадности” ( (там же).

На страницах журнала «Театр и драматургия» о народности Шекспира говорил один из старейших русских театроведов Б. В. Варнеке. В своей статье «Путь к Шекспиру» (Варнеке, 1933ab) (статья представляет собой анализ использования Пушкиным текстов Шекспира) он отмечает, что Пушкин затрагивает вопрос «народности» Шекспира (Варнеке, 1933а: 48).

\section{ИСТОРИЗМ С. А. КРЖИЖАНОВСКОГО}

Научно-исследовательский интерес С. А. Кржижановского к Шекспиру был вызван деятельностью издательства «Асаdemia», в 1931 г. поставившего задачу издать собрания сочинений классиков мировой литературы. В их число вошел и Шекспир. Статья С. А. Кржижановского «Комедии молодого Шекспира» стала предисловием к первому тому собрания (статья не была издана в собрании сочинений по технической причине) 1 . С этого момента начался «шекспировский период» творчества Кржижановского. На протяжении 1930-х годов он написал более десятка статей, выступал с лекциями и докладами о Шекспире. Ава доклада - «Сюжет и стиль шекспировских комедий» и «Об исторических хрониках Шекспира» - были прочитаны им в 1935 г. на заседании автономной секции драматургов при Оргкомитете Союза советских писателей, членом которой он состоял с 1933 г. Стенограммы этих докладов и их обсуждений находятся в Отделе рукописей ИМ ИИ (ОР ИМ ИИ Ф. 52) и РГААИ (РГААИ. Ф. 631) и никогда не издавались.

Наиболее ярким с нашей точки зрения является доклад С.А. Кржижановского «Об исторических хрониках Шекспира» (9 апреля 1935 г.). Мысль Кржижановского предстает в стенограмме доклада и репликах при его обсуждении более живой и самобытный, чем в опубликованной «Поэтике Шекспировских хроник» (Кржижановский, 1936) - расширенной версии этого доклада, что и обусловило наш исследовательский интерес к архивному документу. Аоклад отразил историософские взгляды С. А. Кржижановского и его понимание методологической составляющей в изучении произведений художественной литературы как исторического источника, что выделяет его работы о Шекспире на общем фоне рефлексии творчества этого писателя в России $1930-$ х годов.

В отличие от многих советских писателей, включая М. Горького, С. А. Кржижановский читал Шекспира в оригинале, что создавало необходимые условия для аутентичной интерпретации творчества драматурга. Следует отметить также, что принадлежность С. А. Кржижановского как философа-историка к европейской научной традиции выгодно отличала его подход от политически выверенных, идеологизированных или примитивных концептуальных построений советских литературоведов того времени и именно это послужило основанием не утрачиваемой актуальности и современности его исследований.

Круг проблем, последовательно и разносторонне разбираемых С. А. Кржижановским, поражает широтой охвата: история и поэтика, проблемы перевода и психология творчества. Однако в центре его внимания историзм Шекспира. На этом аспекте мы остановимся подробнее. 
Понятие об истории, которое С. А. Кржижановский вкладывает в свою интерпретацию хроник Шекспира, восходит к проблемам методологии исторического познания в работах немецких философов конца XIX - начала XX в. Крупнейшими философами, занятыми проблемами истории как науки, в конце XIX в. были представители марбургской и баденской школ неокантианства, основателями которых являлись Г. Коген, В. Виндельбанд и Г. Риккерт. Стоит отметить что генезис и развитие философского историзма связаны также с именами хорошо известных в России М. Вебера, В. Аильтея, Г. Зиммеля, О. Шпенглера, Э. Трёльча, Ф. Мейнеке.

В России оригинальными интерпретаторами и продолжателями этого методологического подхода явились историки А. С. Ааппо-Аанилевский, И. М. Гревс и Н. П. Анциферов. Таким образом, связь европейской академической философской мысли с теоретическими и идейными поисками русских ученых в области истории и литературы прослеживается на протяжении долгого времени и не прерывается в 1920-1930-е годы. Можно вспомнить, что у кантианца марбургской школы Г. Когена начинал учиться Б. $\Lambda$. Пастернак. Прямые и косвенные связи немецкой философии (неокантианство, а позднее и феноменология Э. Гуссерля, аутентичным интерпретатором которого в пореволюционной России оставался Г. Г. Шпет) с отечественной гуманитаристикой ХХ в. очевидны.

В ключе, заданном немцами, разворачивался научный дискурс русской мысли, направленный на изучение не только исторических реалий, но и литературно-художественного творчества. Наиболее ярко проблема исторического факта в литературном произведении поставлена С. А. Кржижановским в аналитике исторических хроник У. Шекспира. Особое понимание истории У. Шекспиром, его творческая интерпретация исторического процесса становятся аналитическим материалом для С. А. Кржижановского: «...history Шекспира представляет собой чрезвычайно своеобразную единственную в веках, встречу истории и поэзии. Элементы вымысла, вкрапленные в фактность исторических данных» (ОР ИМАИ. Ф. 52. Оп. 1. Ед. xp. 141. $\Lambda$. 2).

В поиске исторического факта и в попытке дифференцировать приемы изучения фактов подход С. А. Кржижановского (как дитературоведа) сближает его с другим крупнейшим дитературоведом того времени Н. П. Анциферовым, так как они оба исходят из понятия исторической иенности того или иного исторического факта ${ }^{2}$ (Московская, 2012).

По мысли С. А. Кржижановского, драматург производит отбор исторического материала в точности, как историк. Историк - не хронист, не летописец, которые, не разбираясь в материале, сваливают события в кучу. Аля историка отбор факта - центральный момент, момент внесения собственного суждения в материал. Араматург таким же образом отбирает свой материал, собранный очевидцами для «очевидцев», зрителей театра (ОР ИМАИ. Ф. 52. Оп. 1. Ед. хр. 141. А. 5).

На примере различных персонажей Шекспира - как исторических, так и вымышленных - Кржижановский выстраивает внутренние, структурные особенности исторических хроник как поэтику текста посредством анализа и соотношения исторических фактов, их толкования в эпоху Шекспира и через призму фантазии автора, чье воображение, трансформируя исторические факты, соответствуя канону драматического произведения, создает особый, вымышленный мир для своего современника. С. А. Кржижановский утверждает, что, не представляя собственного будущего, зрителю приятно ощущать себя «будущим» для персонажей исторической хроники, следить за драмой «прошлого», переходящей в настоящее. 
Понять и описать движение исторической мысли Шекспира есть задача литературоведа. Кржижановский предпринимает попытку: «Замысел Шекспира, его глубокие поиски произведений во времени имеют определенную цель. Она видна только несколько секунд, только несколько секунд созерцаешь это неопределенное направление туда и обратно, движение исторической мысли Шекспира. О замысле можно догадываться. Он состоит в отыскании на протяжении 100 лет наиболее богатых драматургизмами мест истории. Истории можно задавать самые узловые вопросы. История как земля, как пространственное нечто имеет свою подпочву, почву, надпочву и пыль, и история имеет все, до исторической пыли включительно, и вкапываться в глубину земли можно с различными целями. Историк собирает все факты без критики, потому что трудно наперед сказать, что может пригодиться в момент вывода, а что - нет. Но Шекспир считает драматургизм синтезом наиболее для него выгодным» (ОР ИММИ. Ф. 52. Оп. 1. Ед. хр. 141. А. 1).

Ценности для С. А. Кржижановского в его наблюдениях над историзмом Шекспира раскрываются как в интерпретации истории, так и в создании нового театрального образа. А ценность данного образа определяется благодаря зрителю - реальному участнику реальной истории. Иначе говоря, отбор исторических фактов драматурга будет проверен зрителем. «...Мы можем сказать с полным правом, что пьеса историческая - это гипотеза, направленная на прошлое, - пишет С. А. Кржижановский. Обычно в дальнейшем гипотеза эта проверяется в будущем путем эксперимента. Аля театра специфический эксперимент заключается в показе пьесы, в проверке ее на театре, где и проверяется тысяча гипотез, и в данном случае роль будущего, которое проверяет настоящее, заменяет настоящее, играющее роль будущего - по отношению к прошлым векам 10-летиями и т. А.

Именно к этому настоящему зритель, который чувствует себя смотрящим из будущего на отжитую жизнь, именно к этому настоящему будущему апеллирует Шекспир при проверке исторических фактов, которые он берет из хроник и других источников. Если зритель проверил факт на $<. . .>$ эпоху и не находит точного совпадения, т. е. если он чувствует, что эти старые факты уже изжиты, то значит, их не было. Такой вывод правилен или не правилен - это нас не должно интересовать, но такой театральный вывод делает зритель, и, как зритель, он прав, потому что <... точность будущего перешла в прошедшее» (ОР ИМ АИ. Ф. 52. Оп. 1. Ед. хр. 141. А. 11).

Наш краткий обзор основных особенностей исторической мысли С. А. Кржижановского был призван показать широту его взгляда на проблему методологии истории и продемонстрировать независимость его воззрений. На теоретическом уровне и уровне интуиции он был выше своих современников, придерживающихся социологического (марксистского) понимания исторического факта. Непонимание ими мысли С.А. Кржижановского выразилось в вопросе, заданном ему после выступления: «(С места) Нас интересует вопрос - как наша драматургия могла бы, на основании материалов исторических хроник Шекспира, брать те большие явления, которые происходят?» (ОР ИМАИ. Ф. 52. Оп. 1. Ед. хр. 141. А. 13). Ответ Кржижановского звучал так: «...материал, который мы получили от Шекспира, наше время, имеющее совершенно другой характер, другой цвет, с другого конца спектра, должно использовать очень осторожно. $<\ldots .>$ некоторые приемы Шекспира достаточно для нас значимы, чтобы над ними задуматься и посмотреть, нельзя ли их пустить в работу. В какую? Трудно сказать вперед» (ОР ИМАИ. Ф. 52. Оп . 1. Ед. хр. 141. А. 15). Вряд ли было уместно объяснять присутствующим, что для подражания Шекспиру необходим принципиально иной, чем марксистский, взгляд на историю. 
С. А. Кржижановский был наследником большой культурной традиции русской школы философии в лице А.С. Ааппо-Аанилевского, восходящей к европейской исторической мысли, представленной в 1930-х годах в России (Хализев, 2009). С. А. Кржижановский - прежде всего литературовед, историк словесности, и характеристика его концептуальных положений, связанных с пониманием художественного своеобразия шекспировского историзма, может стать предметом изучения будущих исследований.

\section{ПРИМЕЧАНИЯ}

${ }^{1}$ Статья опубликована не была, послужив основой для другой статьи Кржижановского «Комедиография Шекспира». И она, в свою очередь, не увидела свет при жизни автора и была издана лишь недавно (см.: Кржижановский, 2006: 745-749).

${ }^{2}$ Понятие исторической ценности сопрягалось у Н. П. Анциферова с восприятием некоего события (и (или) легенды) человеческим сообществом, уверовавшим в него или его не принявшим (см.: Московская, 2012: 184).

\section{СПИСОК АИТЕРАТУРЫ}

Варнеке, Б. (1933а) Путь к Шекспиру (начало) // Театр и драматургия. № 1. С. 43-50.

Варнеке, Б. (1933b) Путь к Шекспиру (окончание) // Театр и драматургия. № 2-3. С. 13-17.

Кеменов, В. (1936а) Шекспир в объятиях «социолога» // Аитературный критик. № 1. C. 223-237.

Кеменов, В. (1936b) Классовый характер и народность в творчестве Шекспира // Советское искусство. 5 августа. № 36. С. 2.

Кржижановский, С. (1936) Поэтика Шекспировских хроник // Интернациональная литература. № 1. С. 137-155.

Кржижановский, С. (2006) Собр. соч. : в 6 т. / сост., предисл. и комм. В. Перельмутера. СПб. : Симпозиум. Т. $4.843 \mathrm{c}$.

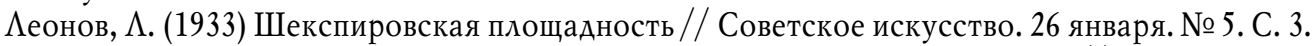

Московская, А. С. (2012) Цокально-исторический метод Н. П. Анциферова // Русское литературоведение XX века: имена, школы, концепции : мат. Межд. науч. конф. (Москва, 26-27 ноября 2010 г.) / под общ. ред. О. А. Клинга, А. А. Холикова. М. ; СПб. : Нестор-История. 320 с. C. $179-185$.

Смирнов, А. А. (1934) Творчество Шекспира. $\Lambda$. : Аен. гос. академ. Большой драматический театр им. М. Горького. 202 с.

Шайтанов, И. О. (2011) История с пропущенными главами: Бахтин и Пинский в контексте советского шекспироведения // Хронотоп и окрестности : Юбилейный сборник в честь Николая Панькова / под ред. Б. В. Орехова. Уфа : Вагант. 388 с. С. 362-379.

Хализев, В. Е. (2009) Теория литературы : учебник для студ. высш. учеб. заведений. 5-е изд., испр. и доп. М. : Изд. центр «Академия». 432 с.

Аата поступления: 2.02 .2015 2.

SIGIZMUND KRZHIZHANOVSKY, THE SCHOLAR OF SHAKESPEARE: STUDYING SHAKESPEARE'S DRAMA IN THE 1930S

(METHODOLOGY AND APPROACH)

\section{K. I. PLOTNIKOV}

(M. Gorky Institute of World Literature, Russian ACADEMy of SCIENCES)

In the late 1920s - the early 1930s, Shakespeare studies in the Soviet Union were dominated by the method of 'vulgar sociology'. This official methodology influenced every scholar of literature. One of the key figures in literary studies of the time was Vladimir M. Friche. 
A change in attitudes to Shakespeare, caused by the general interest in the heritage of classical authors in the Soviet theater, did not occur until 1934.

The article focuses on the yet little researched interpretation of Shakespeare developed in the 1930s by Sigizmund D. Krzhizhanovsky, and his original position in history and cultural scholarship. In particular, we have for the first time analyzed the transcript of Krzhizhanovsky's paper devoted to Shakespeare's chronicles. This document is preserved in Fond No.52, "Vserosskomdram" at the Department of Manuscripts, Institute of World Literature, Russian Academy of Sciences.

The concept of history which underpins Krzhizhanovsky's interpretation of Shakespeare's chronicles can be traced back to the problems of methodology of historical knowledge as advanced by German philosophers of the late 19th and early 20th centuries. Among the original interpreters and followers of this approach in Russia were such historians as A. S. Lappo-Danilevsky, I. M. Grevs and N. P. Antsiferov.

According to Krzhizhanovsky, Shakespeare selected his historical material with an accuracy of a historian. By studying various Shakespearean characters, historical and fictional, Krzhizhanovsky reconstructs the internal structural features of Shakespeare's chronicles as a textual poetics through analysis and correlation of historical facts and their interpretation both by Shakespeare's contemporaries and in the author's imagination. The latter transforms historical facts according to the dramatic canon and creates a fictional world for Shakespeare's contemporary audience. Krzhizhanovsky argues that, not knowing their own future, spectators are pleased to view themselves as 'the future' for historical characters on stage, and to watch the drama of 'the past' proceed into the present.

Keywords: W. Shakespeare, S. D. Krzhizhanovsky, Shakespeare's chronicles, Soviet drama, Soviet Shakespeare studies.

\section{REFERENCES}

Varneke, B. (1933a) Put' k Shekspiru (nachalo) [The path to Shakespeare (beginning)]. Teatr i dramaturgiia, no. 1, pp. 43-50. (In Russ.).

Varneke, B. (1933b) Put' k Shekspiru (okonchanie) [The path to Shakespeare (ending)]. Teatr i dramaturgiia, no. 2-3, pp. 13-17. (In Russ.).

Kemenov, V. (1936a) Shekspir v ob"iatiiakh «sotsiologa» [Shakespeare in the arms of a "sociologist"]. Literaturnyi kritik, no. 1, pp. 223-237. (In Russ.).

Kemenov, V. (1936b) Klassovyi kharakter i narodnost' v tvorchestve Shekspira [The class character and national character in the works of Shakespeare]. Sovetskoe iskusstvo, August 5, no. 36, p. 2. (In Russ.).

Krzhizhanovsky, S. (1936) Poetika Shekspirovskikh khronik [The poetics of Shakespeare's chronicles]. Internatsional' naia literatura, no 1, p. 43. (In Russ.).

Krzhizhanovsky, S. (2006) Sobranie sochinenii [Works]: in 6 vols. / comp., foreword and notes by V. Perel'muter. St. Petersburg, Simpozium Publ. Vol. 4. 843 p. (In Russ.).

Leonov, L. (1933) Shekspirovskaia ploshchadnost' [Shakespeare in the public]. Sovetskoe iskusstvo, 26 January, no. 5, p. 2. (In Russ.)

Moskovskaya, D. S. (2012) Lokal'no-istoricheskii metod N. P. Antsiferova [N. P. Antsiferov's method of local history studies]. In: Russkoe literaturovedenie XX veka: imena, sbkoly, kontseptsii [20 th century Russian literary studies: Personalia, schools, conceptions] : proceedings of International conference (Moscow, November 26-27, 2010) / ed. by O. A. Kling and A. A. Kholikov. Moscow ; St. Petersburg, Nestor-Istoriia Publ. 320 p. Pp. 179-185. (In Russ.).

Smirnov, A. A. (1934) Tvorchestvo Shekspira [Shakespeare's works]. Leningrad, Gorky Leningrad State Academic Bolshoi Drama Theater Publ. 202 p. (In Russ.).

Shaitanov, I. O. (2011) Istoriia s propushchennymi glavami: Bakhtin i Pinskii v kontekste sovetskogo shekspirovedeniia [History with some chapters missing: Bakhtin and Pinsky in the context of the Soviet Shakespeare studies]. In: Kbronotop i okrestnosti : Iubileinyi sbornik $v$ chest' Nikolaia Pan'kova [The chronotope and its surroundings: A festschrift for Nikolai Pan'kov] / ed. by B. V. Orekhov. Ufa, Vagant Publ. 388 p. Pp. 362-379. (In Russ.). 
Khalizev, V. E. (2009) Teoriia literatury [Literary theory] : a textbook for university students. 5 th edn., revised and enlarged. Moscow, Akademiia Publ. Center. 432 p.(In Russ.).

Submission date: 2.02 .2015 .

Плотников Константин Иванович - аспирант, научный сотрудник Отдела рукописей Института мировой литературы РАН. Адрес: 121069, Россия, г. Москва, ул. Поварская, А. 25 А. Тел.: +7 (495) 690-50-30. Эл. почта: k.i.plotnikov@gmail.com. Научный руководитель - А-р филол. наук А. С. Московская.

Plotnikov Konstantin Ivanovich, Postgraduate Student and Research Fellow, Manuscript Department, M. Gorky Institute of World Literature, Russian Academy of Sciences. Postal address: 25A Povarskaya St., 121069 Moscow, Russian Federation. Tel.: +7 (495) 690-50-30. E-mail: k.i.plotnikov@ gmail.com. Research adviser: D. S. Moskovskaya, Doctor of Philology. 